\title{
Investigation of diarrhea in AIDS
}

\author{
Klaus E Mönkemüller MD, C Mel Wilcox MD
}

KE Mönkemüller, CM Wilcox. Investigation of diarrhea in AIDS. Can J Gastroenterol 2000;14(11):933-940. Chronic diarrhea is a common problem in patients with acquired immune deficiency syndrome (AIDS), resulting in significant morbidity and potential mortality. In the early stages of immunodeficiency, human immunodeficiency virus (HIV)-infected patients are susceptible to infection with the same enteric pathogens that cause diarrhea in immunocompetent hosts, but with progressive immunodeficiency, these patients become susceptible to numerous opportunistic disorders. The main factor to consider when tailoring the work-up of diarrhea in the HIV-infected patient is the immune status, which is reflected by the total CD4 lymphocyte cell count. A CD4 count of less than 100 cells/ $\mu \mathrm{L}$ is significantly correlated with opportunistic disorders. For the HIV-infected patient with diarrhea, repeated stool studies to investigate for bacteria, ova and parasites should be the first step. When either upper or lower gastrointestinal tract symptoms are present and stool studies are negative, endoscopy directed to the probable organ of involvement is appropriate. If localizing symptoms are absent, the most appropriate next test is sigmoidoscopy with biopsies. Not infrequently, despite extensive evaluation, the cause of diarrhea in patients with AIDS remains unexplained. Recently, the widespread use of highly active antiretroviral therapy, including protease inhibitors, has led to a change in the epidemiology of diarrhea in AIDS patients. As their immune status improves, HIV-infected patients treated with combination therapy become less prone to opportunistic disorders. However, diarrhea appears to be frequent because several antiretroviral agents can themselves cause diarrhea.

\section{Étude de la diarrhée liée au SIDA}

RÉSUMÉ : La diarrhée chronique est un problème courant chez les patients qui souffrent du syndrome d'immunodéficience acquise (SIDA), le phénomène s'accompagne d'une morbidité importante et d'une mortalité potentielle. Au premier stade de l'immunodéficience, les patients infectés par le VIH sont sujets à l'infection causée par les mêmes organismes pathogènes entériques qui provoquent la diarrhée chez des hôtes immunocompétents. Mais, compte tenu de l'immunodéficience progressive, ces patients deviennent plus sujets à de nombreuses infections opportunistes. Le principal facteur dont il faut tenir compte lorsque l'on ajuste le traitement de la diarrhée chez les patients infectés par le VIH est le statut immunitaire dont témoigne la numération totale des lymphocytes CD4. Une numération de CD4 inférieure à 100/ $\mu \mathrm{L}$ est en corrélation significative avec les troubles opportunistes. Pour les patients infectés par le VIH qui souffrent de diarrhée, des analyses de selles répétées dans le but d'identifier les bactéries, les œufs et les parasites, devraient être la première étape. En présence de symptômes des voies digestives hautes ou basses et de résultats d'analyses de selles négatives, l'endoscopie dirigée vers l'organe probablement atteint est appropriée. En l'absence de symptômes localisés, le test le plus approprié est alors la sigmoïdoscopie avec biopsie. Il n'est pas rare, malgré une évaluation approfondie, que la cause de la diarrhée liée au sida nous échappe. Récemment, l'utilisation répandue de traitements antirétroviraux hautement actifs, y compris les inhibiteurs de la protéase, ont amené des changements dans l'épidémiologie de la diarrhée liée au sida. À mesure que le statut immunitaire des patients infectés par le VIH traités par polythérapie s'améliore, ils deviennent moins sujets aux infections opportunistes. Par contre, la diarrhée semble fréquente, étant donné que plusieurs agents antirétroviraux peuvent la causer.

Key Words: AIDS; Diarrhea; Endoscopy; HIV; Immunodeficiency

This mini-review was prepared from a presentation made at the World Congress of Gastroenterology, Vienna, Austria, September 6 to 11, 1998

Department of Medicine, Division of Gastroenterology and Hepatology, Center for AIDS Research, University of Alabama at Birmingham,

Birmingham, Alabama, USA

Correspondence: Dr C Mel Wilcox, University of Alabama at Birmingham, Division of Gastroenterology and Hepatology, Birmingham, Alabama

35294-0007, USA. Telephone 205-934-6110,fax 205-934-1546,e-mail mel_wilcox@gihep.uab.edu

Received for publication October 4, 1999. Accepted October 12, 1999 
$\mathrm{D}$ iarrhea is a common problem in patients with acquired immune deficiency syndrome (AIDS), occurring in $50 \%$ of human immunodeficiency virus (HIV)-infected patients in North America and up to $100 \%$ of HIV-infected patients living in developing countries (1-3). Chronic diarrhea results in significant morbidity and mortality, reduced quality of life and higher health care expenditures $(4,5)$. In the early stages of immunodeficiency, HIV-infected patients are susceptible to infection by the same enteric pathogens that cause diarrhea in the immunocompetent host, but with progressive immunodeficiency, these patients become susceptible to a wide variety of opportunistic agents (1-3,5). In general, most opportunistic disorders are not observed until the CD4 count falls below 200 cells/ $\mu \mathrm{L}$, and typically less than 100 cells/ $/ \mathrm{L}$ (5).

The widespread use of highly active antiretroviral therapy, which usually includes a protease inhibitor (highly active antiretroviral therapy [HAART]), has affected the epidemiology of diarrhea in AIDS $(6,7)$. As the immune status of HIV-infected patients treated with HAART improves, they become less prone to opportunistic disorders, and the etiology of diarrhea parallels that seen in immunocompetent patients. Also, several antiretroviral agents can themselves cause diarrhea (8). Thus, because of HAART, the management of these patients has changed.

The identification of enteric pathogens is important because of the therapeutic regimens that have become available to treat many of these infections $(1,9,10)$. Despite extensive evaluation, however, a cause of diarrhea in patients with AIDS is not always found (11). Several investigators have proposed various approaches for the work-up of diarrhea in AIDS (12-16). Many of these suggested approaches have been derived from retrospective analysis, and few have been prospectively validated $(12,14)$. A thorough understanding of the etiology, epidemiology and clinical presentation of the various causes of diarrhea in AIDS is essential so that a logical evaluation can be undertaken. In this review, we present current approaches to the evaluation of diarrhea in HIV-infected patients.

\section{ETIOLOGY}

The list of pathogens that can cause diarrhea in patients with AIDS is broad (Table 1), and the most important etiological agents are discussed individually. The most common causes of diarrhea in HIV-infected patients are enteric bacteria, including Shigella flexneri, Salmonella enteritidis, Campylobacter jejuni and Clostridium difficile. Cytomegalovirus (CMV), cryptosporidiosis, microsporidia and Mycobacterium avium complex (MAC) are important pathogens only in patients with advanced immunosuppression (17). Neoplasms such as Kaposi's sarcoma or lymphoma, and fungi such as histoplasmosis are rare causes of diarrhea. More recently, medications, usually protease inhibitors, have become important causes of chronic diarrhea $(5,8)$.

Viruses: CMV is one of the most common opportunistic infections in patients with AIDS, occurring late in the course of HIV infection, when immunodeficiency is severe (CD4
TABLE 1

Enteric pathogens in acquired immune deficiency syndrome

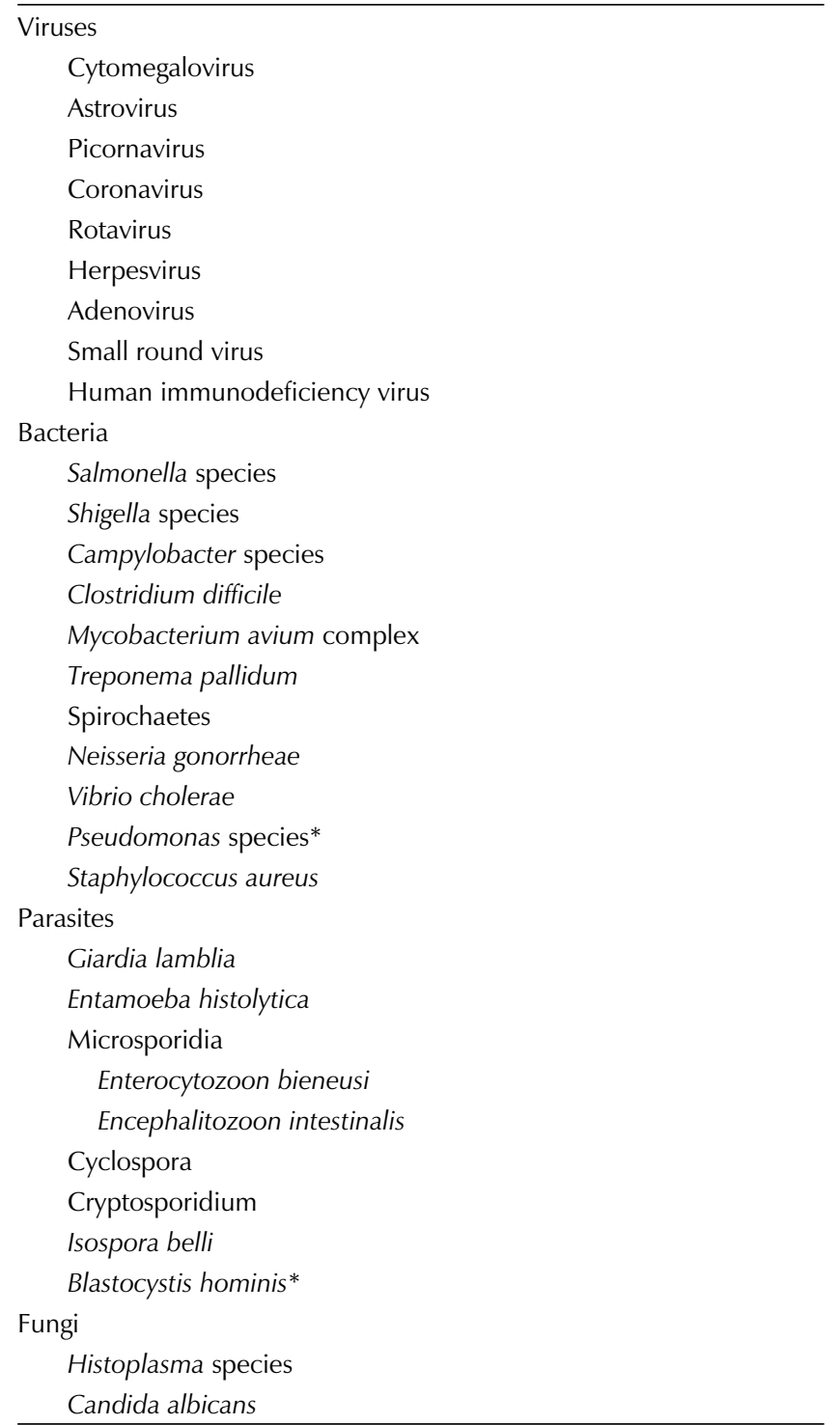

*The pathogenicity of these organisms has been questioned

count less than 100 cells/ $\mu \mathrm{L}(5,7,13,18)$. CMV has been identified in mucosal biopsies in as many as $45 \%$ of patients with AIDS and diarrhea (19-22). A number of other viruses have been reported to involve the gastrointestinal tract in AIDS patients, including adenovirus, rotavirus, astrovirus, picobirna virus and coronavirus (23). There are also reports that HIV itself can be isolated from enterocytes and colonic cells, and that HIV may have a direct cytopathic effect on the intestinal mucosa, resulting in enteropathy (24).

Bacteria: The spectrum of bacterial pathogens causing diarrhea in HIV-infected patients is similar to those that cause diarrhea in the non-HIV-infected host. The most frequently identified pathogens are Campylobacter species, Salmonella species, Shigella species and C difficile $(25,26)$. Yersinia enterocolitica, Staphylococcus aureus and Aeromonas hydrophila have also been associated with severe enterocolitis in HIV- 
infected patients (27). C difficile colitis is a frequent cause of diarrhea in HIV-infected patients, most likely because of the frequent exposure of these patients to antimicrobial agents and their requirement for hospitalization (28). MAC is a common pathogen in AIDS patients with advanced immunosuppression; up to $39 \%$ of patients may develop this infection when the CD4 count remains below 10 cells/ $/ \mathrm{L}$ (29).

Parasites: Among the protozoa, Cryptosporidium parvum is the most common parasite that causes diarrhea in AIDS patients, identified in up to $11 \%$ of symptomatic patients (30). Although it is a cause of acute diarrhea, cryptosporidiosis is most commonly found in HIV-infected patients with chronic diarrhea. Microsporidia (Enterocytozoon bieneusi and Encephalitozoon intestinalis) are also important causes of diarrhea in AIDS patients $(31,32)$. In some studies of HIVinfected patients with chronic diarrhea, microsporidia are the most commonly identified pathogens. In a study from New York (32), microsporidia were found in 39\% of AIDS patients undergoing gastrointestinal evaluation for diarrhea; however, in other areas throughout the world, this pathogen appears to be rare (33). These differences in the prevalence of microsporidiosis are unexplained. Isospora belli is a rare gastrointestinal pathogen in HIV-infected patients in North America, whereas it is endemic in some developing countries such as Haiti (17). Despite a high frequency of stool carriage in asymptomatic homosexual men $(34,35)$, amebic dysentery (35) or invasive amebic disease (ameboma or liver abscess) has rarely been reported in HIV-infected patients $(35,36)$, even in developing countries. Stool carriage of ameba in HIV-infected patients is not limited to nonpathogenic strains of ameba such as Enterococcus dispar, Entamoeba hartmanii and Escherichia coli, but also includes nonpathogenic Entamoeba histolytica (34). Giardiasis is neither more common nor more severe in patients with AIDS than in the nonimmunocompromised host (37).

\section{CLINICAL MANIFESTATIONS}

When evaluating patients with AIDS and diarrhea, an attempt must be made to determine the site of origin of the diarrhea, ie, small bowel ('enteritis') or colon ('colitis'); the clinical history alone is often helpful (37). For example, enteritis classically manifests as large volume (often more than 2 L/day), watery stools, often associated with dehydration, electrolyte disturbances and malabsorption. Abdominal pain, when present, is usually crampy and periumbilical. Symptoms such as nausea, vomiting, bloating, distention and borborygmi are also commonly associated with a small bowel cause of diarrhea. In contrast, colitis is characterized by frequent, small volume stools, which may contain mucus, pus and/or blood, and is often accompanied by 'proctitis' symptoms (tenesmus, frequency, urgency, dyschezia and proctalgia). Abdominal pain is common in colitis and tends to be localized to the lower abdomen. Fever suggests a systemic infection or bacterial infection. A fundoscopic examination may reveal retinitis, which is consistent with CMV infection.

The value of using clinical parameters for tailoring the work-up of diarrhea is under debate. Wilcox et al (12) showed that clinical parameters are useful in predicting which patients may benefit from endoscopic examination. In this study (12), patients with no identifiable pathogen had fewer systemic symptoms (weight loss) and a higher CD4 count. Others, however, have questioned the usefulness of clinical parameters (13). Blanshard et al (13) concluded that the presenting clinical features and hematological and biochemical variables could predict neither the presence nor the site of pathogens. Although there were significant differences in CD4 counts, stool volumes and weight loss between patients with and patients without an identified pathogen, there was such a large overlap that these clinical features could not be used reliably to identify patients most likely to have a pathogen (13). All studies, however, support the value of the CD4 count in stratifying the risk of opportunistic disorders. The only presenting symptom and physical finding that was positively associated with a pathogen (CMV) was abdominal pain. Surprisingly, weight loss and malabsorption did not correlate with the presence of small bowel pathogens (13). Despite these controversies, the history and physical examination remain important parts of the assessment of the patient's general condition and hydration status.

\section{CLINICAL MANIFESTATIONS ACCORDING TO CAUSE}

Viruses: CMV infection of the small bowel and colon is typically accompanied by chronic, watery diarrhea; abdominal pain; wasting; anorexia; fever; and weight loss (37). Most patients with gastrointestinal CMV infection report abdominal pain that is often diffuse. The diarrheal stools may be semiformed or formed, and may be accompanied by bleeding and fecal leukocytes. Gastrointestinal bleeding without diarrhea may be the initial manifestation and results from either severe colitis or isolated well circumscribed ulcers $(38,39)$. When the distal colorectum is involved, symptoms of proctitis may be reported. Toxic megacolon, intestinal perforation, mass lesions and colonic stricture have also been observed as complications of CMV enterocolitis $(37,39)$. Localized or diffuse pain may be elicited on abdominal examination. Other physical findings are nonspecific and primarily reflect CMV-related complications such as dehydration, perforation (acute abdomen) or gastrointestinal bleeding.

The most common colonic manifestation of herpes simplex virus (HSV) in HIV-infected patients is distal proctitis, which may be misinterpreted as diarrhea. If the disease extends to the proximal colon (very rare), proctocolitis with hematochezia and diarrhea may result (37). Most other viruses such as astrovirus, adenovirus and picobirnavirus are accompanied by chronic, watery diarrhea $(23,40)$.

Bacteria: Although bacterial enterocolitis can occur at any stage of immunodeficiency, unusual presentations of these bacterial diseases became apparent early in the AIDS epidemic, when Salmonella species (25) and Campylobacter species bacteremia (26) were reported as initial manifestations of AIDS. In general, however, the clinical presentation of 
TABLE 2

\section{Laboratory tests used to investigate diarrhea in HIV-infected} patients

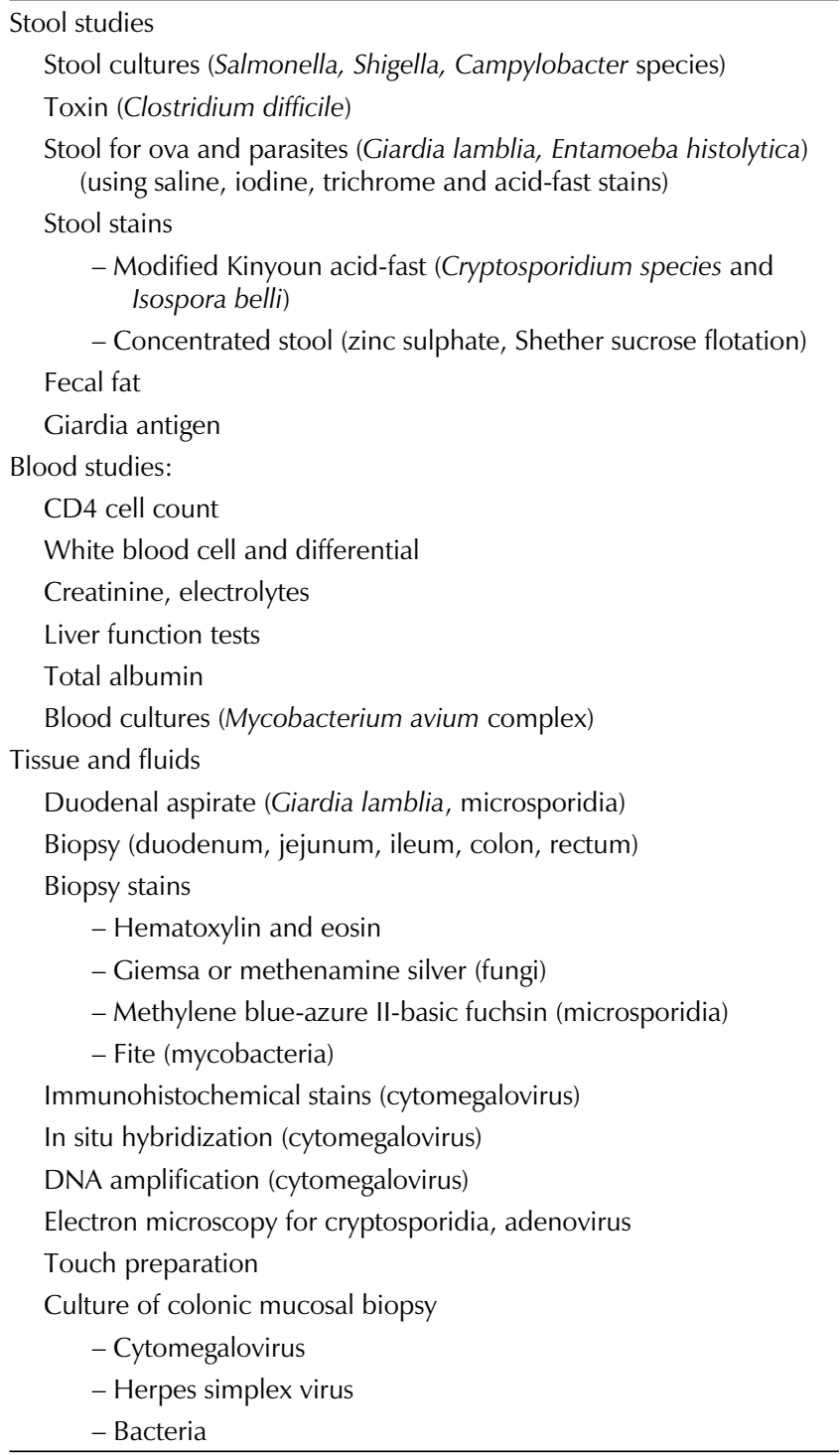

these organisms in patients with AIDS is similar to that in immunocompetent patients. Bacterial enterocolitis manifests as an acute diarrheal illness (less than two weeks' duration). Salmonella gastroenteritis is more commonly associated with watery diarrhea, abdominal pain, fever, nausea and vomiting. Shigella and Campylobacter species are more commonly associated with dysentery, with the classic 'colitis' symptoms - mucopurulent bloody diarrhea, tenesmus and fever. Lower abdominal pain and fever may be prominent, but nausea and vomiting are uncommon. Physical findings include fever, tachycardia and abdominal pain. Digital rectal examination may demonstrate frank blood or pus. Initial experience suggested that the clinical presentation of $\mathrm{C}$ difficile colitis was different in the HIV-infected patient (41), but prospective studies have shown no differences from the presentation in nonimmunocompromised patients (42). C diffi- cile can occur fulminantly without diarrhea, with clinical signs of peritonitis or even ascites (37). The most common manifestation of MAC infection is fever, wasting, chronic diarrhea, abdominal pain, night sweats and intestinal malabsorption (29). Frank colitis or hematochezia, which may be massive, are both uncommon symptoms of gastrointestinal MAC infection (37).

Parasites: Cryptosporidia, microsporidia and I belli are associated with chronic, watery diarrhea; dehydration; malabsorption; and weight loss characteristic of a small bowel diarrhea (17). The illness is more severe in patients with marked immunosuppression and is self-limited if the CD4 count is 200 cells $/ \mu \mathrm{L}$ or higher $(30,31)$. Giardiasis is characteristically associated with chronic diarrhea, abdominal bloating, borborygmi and intermittent abdominal pain.

\section{AVAILABLE TOOLS FOR INVESTIGATION OF DIARRHEA}

The most important tool for evaluating diarrhea in HIV infected patients is the CD4 count because the absolute value reflects the patient's degree of immunodeficiency $(5,9,12,13,20)$. In general, most opportunistic disorders are not observed until the CD4 count falls below 200 cells/ $/ \mathrm{L}$, and more often below 100 cells/ $\mu \mathrm{L}$. Therefore, the evaluation of diarrhea depends on the absolute CD4 count (12). For example, if the CD4 count is higher than 100 cells $/ \mu \mathrm{L}$, evaluation for MAC is not necessary because MAC occurs mainly when the CD4 count is below 50 cells/ $\mu \mathrm{L}$ (29). Likewise, the diagnostic yield of endoscopy in a patient with a CD4 count higher than 200 cells/ $\mu \mathrm{L}$ is low $(12,13)$.

Numerous stool culture media, histopathological stains of mucosal biopsies and molecular tools (eg, polymerase chain reaction) have been employed to identify infectious agents as the cause of diarrhea in HIV-infected patients $(5,9,12,13,43)$. The list of diagnostic tests to evaluate diarrhea in HIV-infected patients is extensive (Table 2); however, it is necessary to use more than a few of these tests.

Stool studies: Stool staining for fecal leukocytes with methylene blue is essential, and their presence suggests that the diarrhea has an inflammatory origin. Stool cultures for Salmonella, Shigella and Campylobacter species, as well as a $\mathrm{C}$ difficile toxin screen, should be routinely submitted. Blanshard et al (13) showed that the yield of stool cultures increases with increasing stool samples (one stool culture is equivalent to $18 \%$, three stool cultures is equivalent to $38.7 \%$ and six stool cultures is equivalent to $46.7 \%$ ). Culturing of colonic mucosal biopsies for enteric bacterial pathogens may increase the diagnostic yield, but its use in routine clinical practice has not been proven (13). Additional stool tests should include examination for ova and parasites, a modified acid-fast stain to evaluate for cryptosporidia and staining for microsporidia. Giardiasis may be difficult to detect on routine stool ova and parasite examination. A stool antigen test for Giardia species is now available (45).

Blood tests and serology: Serological studies for CMV antibodies are not diagnostically helpful in AIDS given the high positivity rate in these patients. Positive cultures of blood or 
bone marrow biopsy establish the diagnosis of disseminated MAC (29) but do not prove active gastrointestinal involvement. Entamoeba species antibody titre (ELISA) is only useful for the evaluation of invasive amebiasis (eg, liver abscess) and not for amebic dysentery.

Radiographic studies: Plain abdominal $\mathrm{x}$-rays are generally nonspecific. In cases of severe colitis, colonic dilation and 'thumbprinting' of the mucosa are observed. Computed tomography may reveal circumferential thickening of the wall of the colon with inflammatory infiltration of the mesentery (37). Barium studies such as small bowel follow-through or barium enema have no role in the evaluation of AIDSrelated diarrhea but may be useful to exclude Crohn's disease. Histology: Histology plays an important role in the diagnosis of most viral, parasitic and fungal causes of diarrhea (46). Cytology, culture and in situ hybridization also appear to be reliable for diagnosing HSV infection. Immunohistochemical stains of mucosal biopsies to confirm various viral infections may be required, but in most cases, their use does not offer an advantage over conventional light microscopy (47). Viral culture of biopsy specimens is generally less sensitive and specific than multiple mucosal biopsies because contamination of the specimen with blood has been reported to cause a falsepositive result (48).

Although electron microscopy of small bowel biopsies is considered the gold standard for the diagnosis of microsporidiosis, recent studies have shown hematoxylin and eosin, Gram stain, Brown-Brenn, Giemsa and modified trichrome staining of small bowel biopsies to have sensitivities of $77 \%$ to $83 \%$, with specificities approaching $100 \%$ (49). In one study (50), use of electron microscopy resulted in the detection of only an additional $4 \%$ of organisms. These results suggest that the additional value of electron microscopy for the detection of parasitic pathogens is negligible.

Endoscopy: Several studies have evaluated the usefulness of upper and lower endoscopy for the evaluation of diarrhea in AIDS $(3,11-13,38)$. The advantage of endoscopy is that it permits direct visualization and mucosal biopsy.

The diagnostic yield of colonoscopy in HIV-infected patients with chronic diarrhea and negative stool studies ranges from $27 \%$ to $37 \%$, with CMV being the most common identified cause. Because CMV infection usually involves the distal colon, sigmoidoscopy with biopsy may be a sufficient work-up for this pathogen $(51,52)$. Nevertheless, in $13 \%$ to $39 \%$ of patients with CMV enterocolitis, the infection can be limited to the right colon. Therefore, if CMV is suspected to be the cause of diarrhea and the distal colon is normal at sigmoidoscopy, a full colonoscopy is warranted (53-55). It is still not clear whether colonoscopy has a higher yield than flexible sigmoidoscopy for the detection of organisms other than CMV $(12,13,38,51)$.

The value of upper endoscopy for the evaluation of chronic diarrhea has been demonstrated $(12,13)$. The most common organisms detected by esophagogastroduodenoscopy (EGD) are cryptosporidia and microsporidia $(12,13)$. Wilcox et al (12) performed EGD with biopsies in HIV-infected patients with chronic diarrhea and nondiagnostic stool tests. In this study (12), a potential pathogen was detected in $44 \%$ of patients. The results of this study reflect what would happen in clinical practice because endoscopy was performed after initial stool studies were negative. In another study of duodenal, ileal and colonic biopsies, cryptosporidia were detected in $53 \%$ of biopsies of patients with previously negative workup by stool studies alone (56). In contrast to previous studies, Blanshard et al (13) published their experience using endoscopy (EGD and flexible sigmoidoscopy) with biopsy as a first-line test in conjunction with noninvasive tests. The usefulness of first-line endoscopy was demonstrated by the high yield $(83 \%)$ of potential pathogens identified during the initial evaluation. Although this more aggressive diagnostic approach resulted in a higher diagnostic yield, it may not be applicable to most clinical practices. More recently, Kearney et al (38) studied 79 patients with chronic diarrhea and negative stool studies. The authors compared the diagnostic yield of a thorough endoscopic work-up (EGD and colonoscopy, which included biopsies of the terminal ileum) with that of the more limited endoscopic approach of flexible sigmoidoscopy in HIV-infected patients with previously negative results from stool studies. An infection was found in 22 of 79 patients (28\%); biopsy of the left colon yielded an enteric pathogen in 17 of these 22 patients and in 15 of 15 patients with CMV colitis. Combined colonic and terminal ileal biopsies missed no pathogens. Duodenal biopsies yielded no additional pathogens beyond those identified by colonoscopy and terminal ileal biopsy. The authors concluded that, for patients with CD4 counts less than $100 \mathrm{cells} / \mu \mathrm{L}$ and chronic unexplained diarrhea, flexible sigmoidoscopy with biopsy was a sufficient endoscopic evaluation (38).

\section{SUMMARY}

There is still no consensus on the most cost effective approach for the evaluation of diarrhea in patients with AIDS, but several well performed studies have proposed a reasonable diagnostic algorithm. Various authors $(1,9,15,16)$, and more recently the American Gastroenterology Association (5), have proposed a stepwise approach for the evaluation of chronic diarrhea in AIDS. The first step includes at least three sets of stool samples to investigate for bacterial pathogens (Salmonella, Campylobacter and Shigella species) and parasites (cryptosporidia and microsporidia). Testing for $\mathrm{C}$ difficile is recommended for patients at risk for this infection (use of antibiotics, recent hospitalization). In HIVinfected patients with a CD4 count less than 100 cells $/ \mu \mathrm{L}$ and fever, blood cultures should be drawn to investigate for MAC. If these tests are negative, the second step is to perform a flexible sigmoidoscopy. Colonoscopy was recommended only in select patients (ie, patients with marked immunosuppression and clinical manifestations of dehydration, wasting, diffuse abdominal pain) $(5,51)$. If no cause could be determined after steps 1 and 2 were performed, proceeding with EGD and biopsy of the duodenum to exclude microsporidia and cryptosporidia was recommended $(5,51)$.

From the available literature, it is evident that endoscopy 
TABLE 3

Drugs used in the treatment of diarrhea in patients with acquired immune deficiency syndrome

\begin{tabular}{|c|c|c|c|}
\hline Infection & Treatment & Dosage & Duration \\
\hline \multirow[t]{2}{*}{ Cytomegalovirus } & Ganciclovir & $5 \mathrm{mg} / \mathrm{kg}$ bid & 2-4 weeks \\
\hline & Foscarnet & $90 \mathrm{mg} / \mathrm{kg}$ bid & 2-4 weeks \\
\hline \multirow[t]{4}{*}{$\begin{array}{l}\text { Herpes simplex } \\
\quad \text { virus }\end{array}$} & Acyclovir & $\begin{array}{l}400-800 \mathrm{mg} \\
(5 \text { times/day) }\end{array}$ & 14 days \\
\hline & Foscarnet & $60-90 \mathrm{mg} / \mathrm{kg}$ bid & 14 days \\
\hline & Valacyclovir & $500 \mathrm{mg}$ tid & 14 days \\
\hline & Famciclovir & $500 \mathrm{mg}$ bid & 7-10 days \\
\hline \multirow[t]{6}{*}{ Cryptosporidia } & $\begin{array}{l}\text { No definite } \\
\text { therapy known }\end{array}$ & & \\
\hline & Paromomycin & $25-35 \mathrm{mg} / \mathrm{kg}$ tid & 14-28 days \\
\hline & Spiramycin & $1 \mathrm{~g}$ tid & 14-28 days \\
\hline & Azithromycin & 900 mg/day & 14-28 days \\
\hline & Letrazuril & 50-100 mg/day & 14-28 days \\
\hline & Bovine colostrum & $50 \mathrm{~g} /$ day & 14-28 days \\
\hline \multicolumn{4}{|l|}{ Microsporidia } \\
\hline $\begin{array}{l}\text { Septata } \\
\text { intestinalis }\end{array}$ & Albendazole & $400 \mathrm{mg}$ bid & 14-28 days \\
\hline \multirow[t]{3}{*}{$\begin{array}{l}\text { Enterocytozoon } \\
\text { species }\end{array}$} & $\begin{array}{l}\text { No definite } \\
\text { therapy known }\end{array}$ & & \\
\hline & Albendazole & $400 \mathrm{mg}$ bid & $14-28$ days \\
\hline & Metronidazole & $500 \mathrm{mg}$ tid & 14-28 days \\
\hline Isospora belli & TMP-SMX DS & 1 tablet qid & 10-14 days \\
\hline Cyclospora & TMP-SMX DS & 1 tablet qid & 10-14 days \\
\hline Giardia lamblia & Metronidazole & $500 \mathrm{mg}$ tid & 10-14 days \\
\hline \multirow{2}{*}{$\begin{array}{l}\text { Entamoeba } \\
\text { histolytica }\end{array}$} & Metronidazole & $750 \mathrm{mg}$ tid & 10-14 days \\
\hline & Iodoquinol & $650 \mathrm{mg}$ tid & 10-14 days \\
\hline $\begin{array}{l}\text { Mycobacterium } \\
\text { avium complex }\end{array}$ & $\begin{array}{l}\text { Clarithromycin, } \\
\text { EMB, } \\
\text { Ciprofloxacin, } \\
\text { RFP }\end{array}$ & $500 \mathrm{mg}$ bid & 4 weeks \\
\hline \multirow[t]{2}{*}{ Clostridium difficile } & Metronidazole & $500 \mathrm{mg}$ tid & 10-14 days \\
\hline & Vancomycin & $250 \mathrm{mg}$ qid & 10-14 days \\
\hline \multirow[t]{2}{*}{ Salmonella species } & Ciprofloxacin & $500 \mathrm{mg}$ bid & 10-14 days \\
\hline & TMP-SMX DS & 1 tablet qid & 10-14 days \\
\hline \multirow[t]{2}{*}{ Shigella species } & Ciprofloxacin & $500 \mathrm{mg}$ bid & 10-14 days \\
\hline & Ampicillin & 500 mg qid & 10-14 days \\
\hline \multirow{2}{*}{$\begin{array}{c}\text { Campylobacter } \\
\text { species }\end{array}$} & Ciprofloxacin & $500 \mathrm{mg}$ bid & 10-14 days \\
\hline & Erythromycin & 500 mg qid & 7-14 days \\
\hline
\end{tabular}

DS Double strength; EMB Ethambutol; RFP Rifampicin; TMP-SMX Trimethoprim sulphamethoxazole

plays an important role in the work-up of HIV-infected patients with chronic diarrhea. The main question regarding endoscopy is, 'at what point during the work-up of diarrhea should it be performed?' Although a stepwise approach seems reasonable when evaluating these patients, it may not be the best approach, given the high diagnostic yield when performing stool studies combined with upper and lower endoscopy (13). Nevertheless, this aggressive approach may not be widely applicable given that routine clinical practice stool studies are relatively inexpensive, noninvasive and often positive. We still believe that stool studies should generally be obtained before endoscopic evaluation.

When all tests are negative, symptomatic therapy with antidiarrheal agents is frequently successful in alleviating symptoms (40). Occasionally, despite antimicrobial treatment of an identified pathogen, the diarrhea may continue. Under this circumstance, further investigations are warranted because the patient may be coinfected with other pathogens or have another cause for the diarrhea. The value of quantifying fecal fat and measuring D-xylose absorption in HIV-infected patients with chronic diarrhea has not been established. An important point that deserves attention is that, despite various approaches to the work-up of diarrhea in AIDS, a significant number of patients remain without an established diagnosis.

\section{THERAPY}

The objective of this article was to emphasize the investigation of diarrhea in patients AIDS; therefore, the reader is referred to recent publications on the therapy for gastrointestinal infections in AIDS (57). A table with the current drugs and dosages, and duration of therapy for the most common gastrointestinal pathogens is provided (Table 3 ).

\section{CONCLUSIONS AND RECOMMENDATIONS}

A thorough history and physical examination are essential for evaluating the patient's general condition and help focus the work-up of diarrhea in patients with AIDS. In addition, routine blood tests may be useful to evaluate objectively the severity of the diarrhea, such as hydration status and electrolyte disturbances. A markedly elevated white blood cell count suggests bacterial colitis or a complication such as perforation or intra-abdominal abscess formation. Nevertheless, the main factor to consider when tailoring the algorithm(s) for the work-up of diarrhea in the HIV-infected patient is the immune status, as reflected by the absolute CD4 count. We believe that a stepwise approach is reasonable and that the first step should include stool studies. Although the positivity rate increases with the number of submitted samples, obtaining three or more samples is often difficult. We recommend obtaining at least one complete set; additional stool samples may be appropriate to exclude parasitic diseases in the patient who is not critically ill or who has no localizing symptoms. From the published evidence, it is clear that invasive tests such as endoscopy with biopsy should be performed sooner rather than later in patients in whom noninvasive tests are nondiagnostic, especially those with CD4 counts less than 100 cells/ $/ \mathrm{L}$. When either upper or lower gastrointestinal tract symptoms are present and stool studies are negative, endoscopy directed to the probable organ of involvement is appropriate (12). If the patient is undergoing a colonoscopy and there is additional suspicion for microsporidia, an attempt should be made to intubate and biopsy the terminal ileum during colonoscopy because the yield of detecting microsporidia may be equivalent to that with EGD with small bowel biopsies (38). If it is not possible to localize 
the symptoms to the upper or lower gastrointestinal tract in an AIDS patient with diarrhea and stool studies are negative, the most appropriate test is sigmoidoscopy with biopsy $(38,51)$.

The epidemiology of diarrhea in AIDS is changing in this era of HAART (7). Combination antiretroviral therapy has been shown to lead to resolution of diarrhea caused by organisms such as microsporidia and cryptosporidia (58). In addition, combination antiretroviral therapy improves the immune status of the HIV-infected patient, making them less susceptible to opportunistic disorders. In most patients

\section{REFERENCES}

1. Smith PD, Quinn TC, Strober W, Janoff EN, Masur H. Gastrointestinal infections in AIDS. Ann Intern Med 1992;116:63-77.

2. Colebunders R, Francis H, Mann JM, et al. Persistent diarrhea, strongly associated with HIV-infection in Kinshasa, Zaire. Am J Gastroenterol 1987;82:859-64.

3. Mayer HB, Wanke CA. Diagnostic strategies in HIV-infected patients with diarrhea. AIDS 1994;8:1639-48.

4. Lubeck DP, Bennett CL, Mazonson PD, et al. Quality of life and health service use among HIV-infected patients with chronic diarrhea. J Acquir Immune Defic Syndr 1993;6:478-84.

5. Wilcox CM, Rabeneck L, Friedman S. AGA technical review: Malnutrition and cachexia, chronic diarrhea, and hepatobiliary disease in patients with human immunodeficiency virus infection. Gastroenterology 1996;111:1724-52.

6. Call S, Mönkemüller K, Saag M, Wilcox CM. The changing etiology of diarrhea in patients with the acquired immune deficiency syndrome (AIDS). Am J Gastroenterol 1998;63:1665. (Abst)

7. Mönkemüller KE, Call S, Lazenby AJ, Wilcox CM. Striking fall in the prevalence of gastrointestinal cytomegalovirus disease in the acquired immune deficiency syndrome: Reflections of a 'Maytag repair man'. Am J Gastroenterol 1998;93:1669.

8. Moyle GJ, Youle M, Higgs C, et al. Safety, pharmacokinetics, and antiretroviral therapy of the potent, specific human immunodeficiency virus protease inhibitor nelfinavir: results of a phase I/II trial and extended follow-up in patients infected with human immunodeficiency virus. J Clin Pharmacol 1998;38:736-43.

9. Smith PD, Lane HC, Gill VJ, et al. Intestinal infections in patients with the acquired immunodeficiency syndrome (AIDS). Etiology and response to therapy. Ann Intern Med 1988;108:328-33.

10. Wilcox CM, Mönkemüller KE. Treatment of gastrointestinal infections in HIV-infected patients. Aliment Pharmacol Ther 1997;11:425-43.

11. Connolly GM, Forbes A, Gazzard BG. The investigation of apparently pathogen-negative diarrhoea in patients infected with human immunodeficiency virus (HIV-1). Gut 1990;31:886-9.

12. Wilcox CM, Schwartz DA, Costonis G, Thompson SE. Chronic unexplained diarrhea in human immunodeficiency virus infection: determination of the best diagnostic approach. Gastroenterology 1996;110:30-7.

13. Blanshard C, Francis N, Gazzard BG. Investigation of chronic diarrhoea in acquired immunodeficiency syndrome. A prospective study in 155 patients. Gut 1996;39:824-32.

14. Greenson JK. AIDS enteropathy: occult enteric infections and duodenal mucosal alterations in chronic diarrhea. Ann Intern Med 1991;114:366-72.

15. Johanson JF, Sonnenberg A. Efficient management of diarrhea in the acquired immunodeficiency syndrome (AIDS). A medical decision analysis. Ann Intern Med 1990;1:942-8.

16. René E, Marche C, Regnier B, et al. Intestinal infections in patients with the acquired immunodeficiency syndrome: a prospective study in 132 patients. Dig Dis Sci 1989;34:773-80.

17. Goodgame RW. Understanding intestinal spore-forming protozoa: Cryptosporidia, microsporidia, isospora, and cyclospora. Ann Intern Med 1996;124:429-41.

18. Gallant JE, Moore RD, Richman DD, et al. Incidence and natural history of cytomegalovirus disease in patients with advanced human immunodeficiency virus disease treated with zidovudine. J Infect Dis 1992;166:1223-7. taking HAART in whom chronic diarrhea resolves, a rise in CD4 count has been observed, but in a significant number of patients, the diarrhea resolves despite a persistently low CD4 count, suggesting that HAART may improve immunity by mechanisms other than increasing CD4 cells. In this era of HAART, the infectious causes of diarrhea appear to be decreasing, whereas diarrhea secondary to the use of antiretroviral agents such as protease inhibitors is increasingly common (6). The implications of these changes in the overall management of HIV-infected patients with diarrhea require further study.

19. Frank D, Raicht RF. Intestinal perforation associated with cytomegalovirus infection in patients with acquired immunodeficiency syndrome. Am J Gastroenterol 1984;79:201-5.

20. Dieterich DT, Chachoua A, Lafleur F, et al. Ganciclovir treatment of gastrointestinal infections caused by cytomegalovirus in patients with AIDS. Rev Infect Dis 1988;10:532-7.

21. Peters BS, Beck EJ, Anderson S, et al. Cytomegalovirus infection in AIDS. Patterns of disease, response to therapy and trends in survival. J Infect 1991;23:129-37.

22. Dieterich DT, Kotler DP, Busch DF, et al. Ganciclovir treatment of cytomegalovirus colitis in AIDS: A randomized, double-blind, placebo-controlled multicenter study. J Infect Dis 1993;167:278-82.

23. Grohmann GS, Glass RI, Pereira HG, et al. Enteric viruses and diarrhea in HIV-infected patients. N Engl J Med 1993;329:14-20.

24. Dobbins WO III, Weinstein WM. Electron microscopy of the intestine and rectum in acquired immunodeficiency syndrome. Gastroenterology 1985;88:738-43.

25. Smith PD, Macher AM, Bookman MA, et al. Salmonella typhimurium enteritis and bacteremia in the acquired immunodeficiency syndrome. Ann Intern Med 1985;102:207-9.

26. Molina JM, Casin I, Hausfater P, et al. Campylobacter infections in HIV-infected patients: clinical and bacteriological features. AIDS 1995;9:881-5.

27. Roberts IM, Parenti DM, Albert MB. Aeromonas hydrophila-associated colitis in a male homosexual. Arch Intern Med 1987;147:1502-3.

28. Hutin Y, Molina JM, Casin I, et al. Risk factors for Clostridium difficile-associated diarrhoea in HIV-infected patients. AIDS 1993;7:1441-7.

29. Havlik JA, Horsburgh CR, Metchock B, et al. Disseminated Mycobacterium avium complex infection: clinical identification and epidemiologic trends. J Infect Dis 1992;165:577-80.

30. Connolly GM, Dryden MS, Shanson DC, Gazzard BG. Cryptosporidial diarrhea in AIDS and its treatment. Gut 1988;29:593-7.

31. Molina JM, Sarfati C, Beauvais B, et al. Intestinal microsporidiosis in human immunodeficiency virus-infected patients with chronic unexplained diarrhea: Prevalence and clinical and biologic features. J Infect Dis 1993;167:217-21.

32. Kotler DP, Orenstein JM. Prevalence of intestinal microsporidiosis in HIV-infected individuals referred for gastroenterological evaluation. Am J Gastroenterol 1994;89:540-6.

33. Mönkemüller KE, Bussian AH, Lazenby A, Wilcox CM. Diarrhea in human immunodeficiency virus infected patients: where did all the microsporidia go? Gastroenterology 1998;114:A1042. (Abst)

34. Allason-Jones E, Mindel A, Sargeaunt P, Williams P. Entamoeba histolytica as a commensal intestinal parasite in homosexual men. N Engl J Med 1986;315:353-6.

35. Ohnishi K, Murata M, Okuzawa E. Symptomatic amebic colitis in a Japanese homosexual AIDS patient. Intern Med 1994;33:120-2.

36. Sturgess I, Greenfield SM, Teare J, et al. Ulcerative colitis developing after amoebic dysentery in a hemophiliac patient with AIDS. Gut 1992;33:408-10.

37. Mönkemüller KE, Wilcox CM. Diagnosis and treatment of colonic disease in AIDS. Gastrointest Endosc Clin North Am 1998;8:889-911.

38. Kearney DJ, Steuerwald M, Koch J, Cello JP. A prospective study of endoscopy in HIV-associated diarrhea. Am J Gastroenterol 1999;94:596-602.

39. Escudero-Fabre A, Cummings O, Kirklin JK, et al. Cytomegalovirus 
colitis presenting as hematochezia and requiring resection. Arch Surg 1992;127:102-4

40. Lew EA, Poles MA, Dieterich DT. Diarrheal diseases associated with HIV infection. Gastrointest Clin North Am 1997;26:259-90.

41. Cozart JC, Kalangi SS, Clench MH, et al. Clostridium difficile diarrhea in patients with AIDS versus non-AIDS controls. J Clin Gastroenterol 1993;16:192-4.

42. Lu SS, Schwartz JM, Simon DM, et al. Clostridium difficile-associated diarrhea in patients with HIV positivity and AIDS: a prospective controlled study. Am J Gastroenterol 1994;89:1226-9.

43. Simon D, Kotler DP, Brandt LJ. Chronic unexplained diarrhea in human immunodeficiency virus infection: Determination of the best diagnostic approach. Gastroenterology 1996;111:269-70.

44. Beaugerie L, Salauze B, Buré A, et al. Utility of culturing colonic mucosa in HIV-infected patients with diarrhea. Gastrointest Endosc 1996;44:663-6.

45. Addiss DG, Mathews HM, Stewart JM, et al. Evaluation of a commercially available enzyme-linked immunosorbent assay for Giardia lamblia antigen in stool. J Clin Microbiol 1991;29:1137-42.

46. Culpepper-Morgan JP, Kotler DP, Scholes JV, et al Evaluation of diagnostic criteria for mucosal cytomegalic inclusion disease in the acquired immune deficiency syndrome. Am J Gastroenterol 1987;82:1264-70.

47. Mönkemüller KE, Bussian AH, Lazenby A, Wilcox CM. Role of special stains in the pathologic evaluation of human immunodeficiency virus (HIV)-related gastrointestinal infections. Gastroenterology 1998;114:A1042. (Abst)

48. Goodgame RW, Genta RM, Estrada R, Demmler G, Buffone G. Frequency of positive tests for cytomegalovirus in AIDS patients: endoscopic lesions compared with normal mucosa. Am J Gastroenterol 1993;88:338-43.
49. Weber R, Bryan RT, Owen RL, Wilcox CM, Gorelkin L, Visvesvara GS. Improved light-microscopical detection of microsporidia spores in stool and duodenal aspirates. N Engl J Med 1992;326:161-6.

50. Kotler DP, Giang TT, Garro ML, Orenstein JM. Light microscopic diagnosis of microsporidiosis in patients with AIDS. Am J Gastroenterol 1994;89:540-4.

51. Bini EJ. Endoscopic approach to HIV-associated diarrhea: How far is far enough? Am J Gastroenterol 1999;94:556-9.

52. Combes R, Vallot T, Marche C, et al. Diagnostic de colite a cytomegalovirus au cours du SIDA. Valeur comparative de la coloscopie totale et de la rectosigmoidoscopie (a propos de 24 cas). Presse Med 1995;24:572-6.

53. Wilcox CM, Chalasani N, Lazenby A, et al. Cytomegalovirus colitis in acquired immunodeficiency syndrome: A clinical and endoscopic study. Gastrointest Endosc 1998;48:39-43.

54. Bini EJ, Weinshel EH. Endoscopic evaluation of chronic human immunodeficiency virus-related diarrhea: is colonoscopy superior to flexible sigmoidoscopy? Am J Gastroenterol 1998;93:56-60.

55. Dieterich DT, Rahmin M. Cytomegalovirus colitis in AIDS: presentation in 44 patients and a review of the literature. J Acquir Immune Defic Syndr 1991;1:S29-35.

56. Bini EJ, Cohen J. Diagnostic yield and cost-effectiveness of endoscopy in chronic human immunodeficiency virus-related diarrhea. Gastrointest Endosc 1998;48:354-61.

57. Wilcox CM, Mönkemüller KE. Management of gastrointestinal infections in AIDS. In: Dolin R, Masur H, Saag M, eds. AIDS Therapy. New York: Churchill Livingstone Inc, 1999:752-65.

58. Carr A, Marriott D, Field A, Vasak E, Cooper DA. Treatment of HIV-1 associated microsporidiosis and cryptosporidiosis with combination antiretroviral therapy. Lancet 1998;351:256-61. 


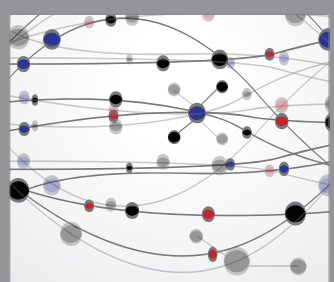

The Scientific World Journal
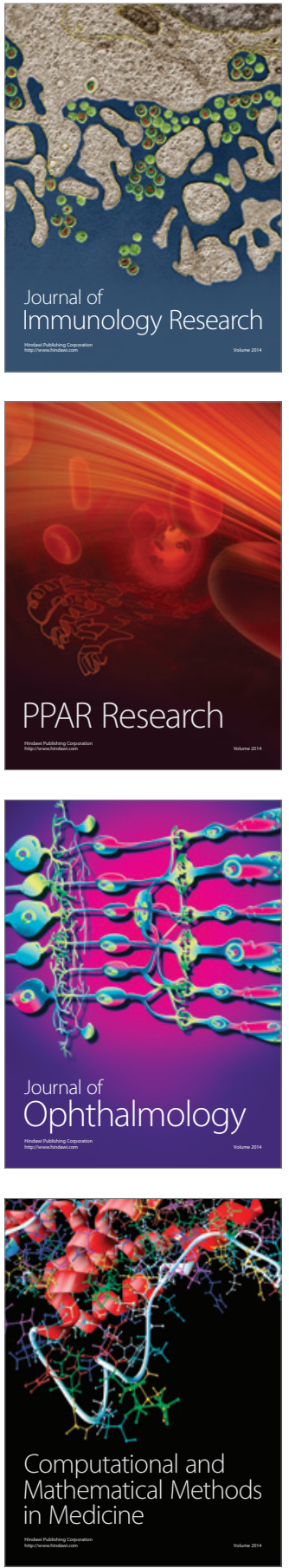

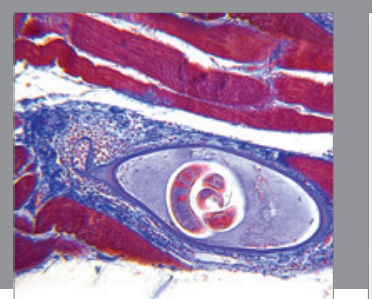

Gastroenterology Research and Practice

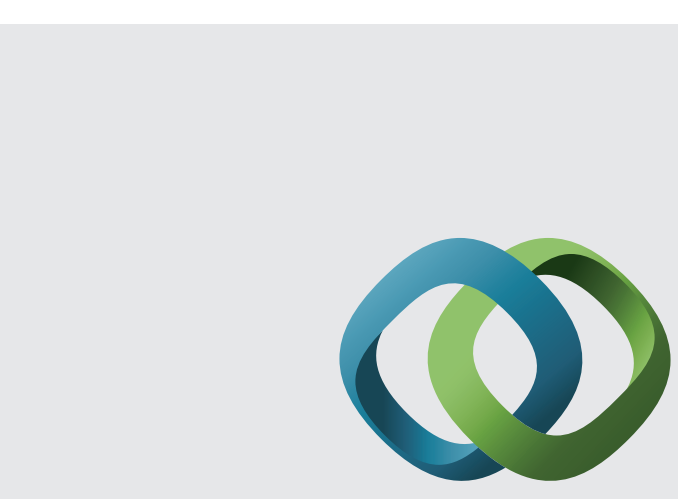

\section{Hindawi}

Submit your manuscripts at

http://www.hindawi.com
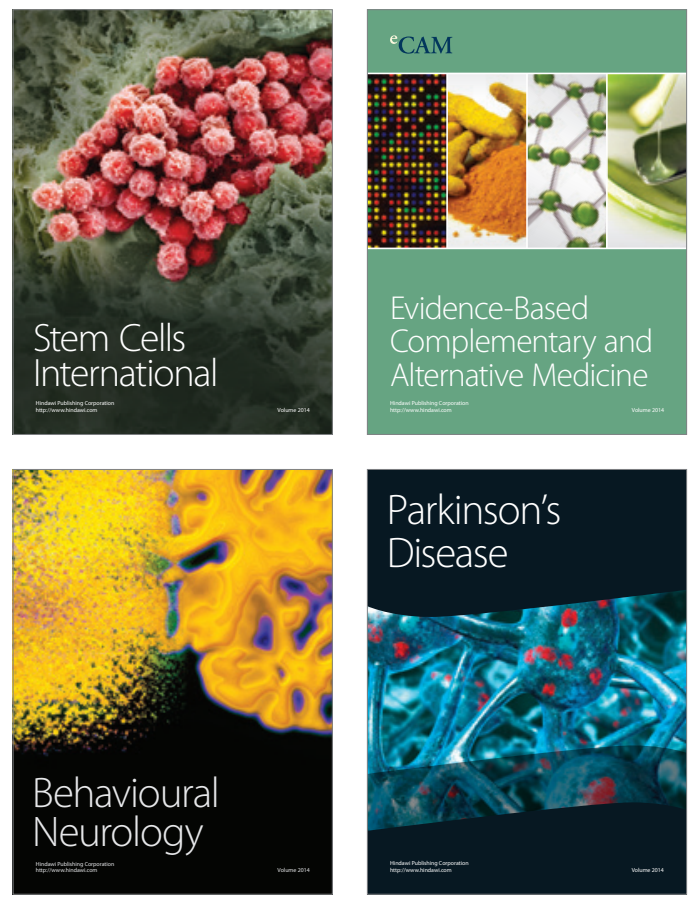
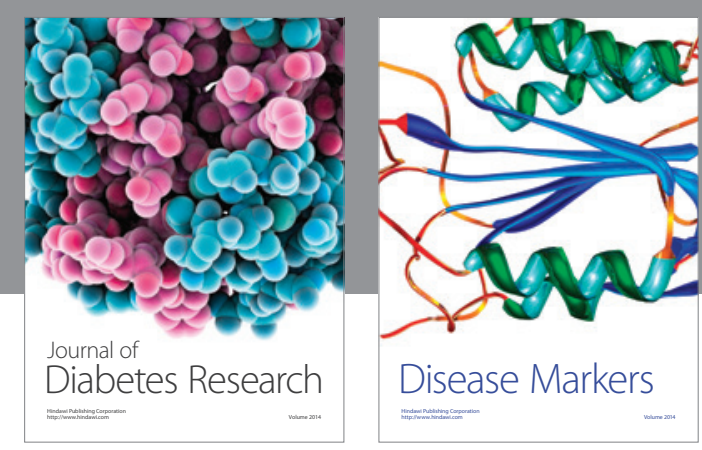

Disease Markers
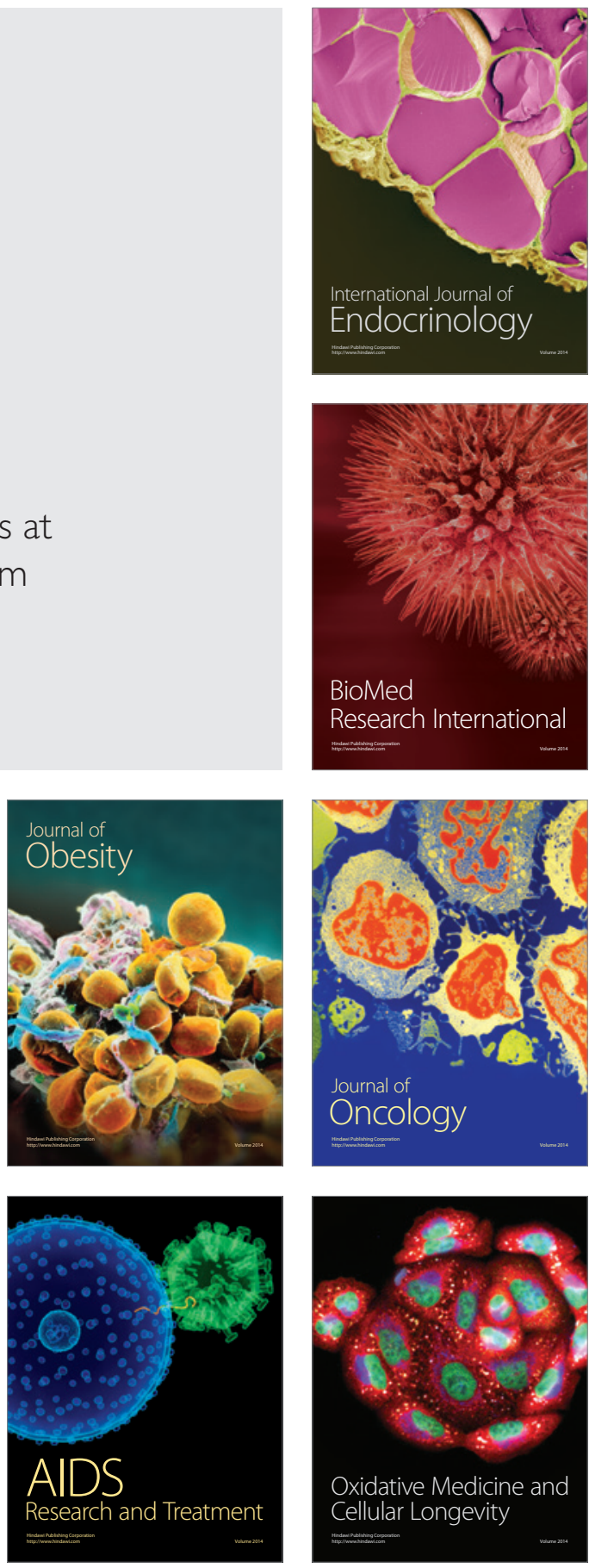